Printed in Great Britain

\title{
THIN FILM PC-EL TYPE SYSTEM WITH CHOPPER IN THE PATH OF OPTICAL FEEDBACK
}

\author{
Z. PORADA \\ Institute of Electrical Engineering and Electronics, Technical University, Warszawska 24, \\ 31-155 Kraków, Poland \\ E. SCHABOWSKA-OSIOWSKA \\ Department of Physics and Electron Technology, Institute of Electronics, Academy of \\ Mining and Metallurgy, Al. Mickiewicza 30, 30-059 Kraków, Poland
}

(Received March 22, 1989; in final form May 1, 1989)

\section{INTRODUCTION}

Thin film systems of PC-EL type obtained by series connection of a photoconducting element $/ \mathrm{PC} /$ with an electroluminescent cell /EL/ are interesting because of their possible application for various kinds of optoelectronic systems. ${ }^{1,2}$

Particularly interesting are PC-EL systems with optical feedback, which at suitable high values of the feedback coefficient can be of bi-stable character.

High values of the feedback coefficient are technically difficult to obtain. However, at low values of this coefficient, it is possible to obtain a bistable system if a chopper is employed in the path of optical feedback.

\section{THEORETICAL CONSIDERATIONS}

For analysis of properties of thin film PC-EL system with optical feedback, a theoretical model ${ }^{3}$ developed on the basis of an equivalent circuit shown in Fig. 1 was investigated.

The admittance $\mathrm{Y}_{\mathrm{EL}}$ of an electroluminescent cell is described by the formula:

$$
\mathrm{Y}_{\mathrm{EL}}=\mathrm{G}_{\mathrm{EL}}+\mathrm{j} \omega \mathrm{C}_{\mathrm{EL}}
$$




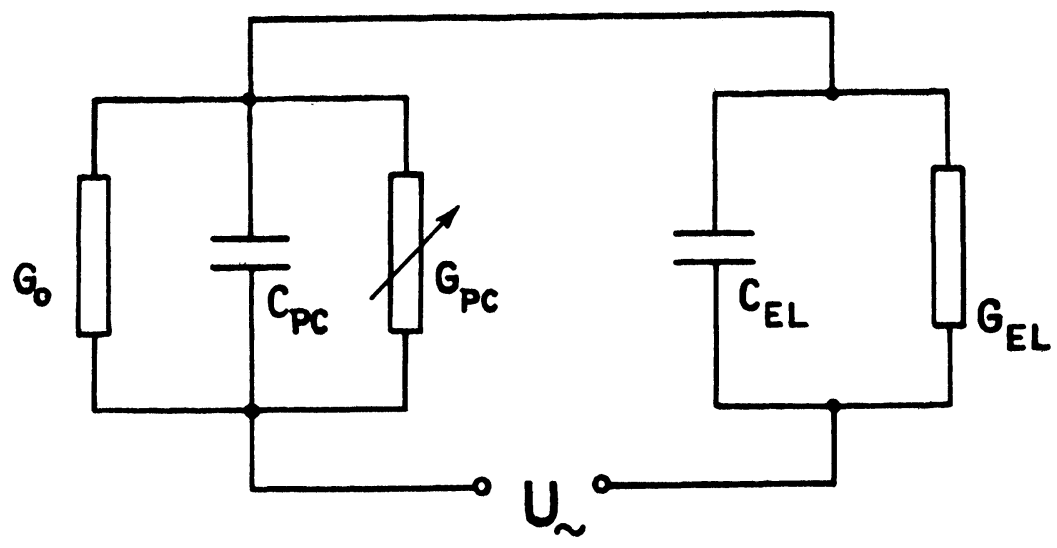

FIGURE 1 Equivalent circuit of a PC-EL system.

where $\omega=2 \pi \mathrm{f}, \mathrm{f}$ is the frequency of the alternating exciting sinusoidal voltage, $\mathrm{G}_{\mathrm{EL}}$ is the leakage conductance of the electroluminescent cell and $\mathrm{C}_{\mathrm{EL}}$ is the capacitance of the cell.

The admittance $\mathrm{Y}_{\mathrm{PC}}$ of a photoconductive element is given ${ }^{4}$ by the formula:

$$
\mathrm{Y}_{\mathrm{PC}}=\mathrm{G}_{0}+\mathrm{g}_{1}\left(1+\omega^{2} \tau^{2}\right)^{-1} \mathrm{~L}_{\mathrm{TOT}}+\mathrm{j \omega} \mathrm{C}_{\mathrm{PC}}
$$

where $G_{0}$ is the "dark" conductance of the photoconductive element, $g_{1}$ and $\tau$ are parameters that are constant for a given photoconductive element, $\mathrm{C}_{\mathrm{PC}}$ is the capacitance of the element and $\mathrm{L}_{\mathrm{TOT}}$ is the total illumination of the element.

For a thin film PC-EL system with optical feedback,

$$
\mathrm{L}_{\mathrm{TOT}}=\mathrm{L}+\beta \mathrm{B}
$$

where $\mathrm{L}$ is the external illumination, $\mathrm{B}$ is the luminance of the light emitted by an electroluminescent cell and $\beta$ is a constant, determined by geometry and by the degree of spectral overlap of the electroluminescent cell and the photoconductive element.

The instance of the break in the path of optical feedback, the coefficient $\beta=0$. 
To describe the luminance B of the electroluminescent cell, Alfrey and Taylor's ${ }^{5}$ formula was used:

$$
\mathrm{B}=\mathrm{B}_{0} \exp \left(\frac{-\gamma \pi}{2 \omega}\right) \exp \left(-\mathrm{b} \mathrm{U}_{\mathrm{EL}}^{-1 / 2}\right)
$$

where $\mathrm{B}_{0}, \gamma$, and $\mathrm{b}$ are constant parameters for a given electroluminescent cell,

$$
\mathrm{U}_{\mathrm{EL}}=\left|\frac{\mathrm{Y}_{\mathrm{PC}}}{\mathrm{Y}_{\mathrm{EL}}+\mathrm{Y}_{\mathrm{PC}}}\right| \mathrm{U}_{0}
$$

and $\mathrm{U}_{0}$ is the amplitude of the applied sinusoidal voltage.

For a real PC-EL system, three additional simplifying assumptions are usually fulfilled:

$$
\mathrm{C}_{\mathrm{PC}} \ll \mathrm{C}_{\mathrm{EL}} ; \quad \omega \mathrm{C}_{\mathrm{EL}} \gg \mathrm{G}_{0} ; \quad \omega \mathrm{C}_{\mathrm{EL}} \gg \mathrm{G}_{\mathrm{EL}} .
$$

Then the dependence of the average value of the luminance $B$ on the external intensity $\mathrm{L}$ of illumination can be expressed as follows:

$$
\begin{aligned}
B=B_{0} & \exp \left(\frac{-\gamma \pi}{2 \omega}\right) \\
& \exp \left\{\frac{-b}{\sqrt{U_{0}}}\left(1+\left[\frac{\omega C_{E L}}{G_{0}+g_{1}(L+\beta B)\left(1+\omega^{2} \tau^{2}\right)^{-1}}\right]^{2}\right)^{1 / 4}\right\}
\end{aligned}
$$

The characteristics calculated from eq. (5), the dependence of the luminance B on the external illumination L, are shown in Fig. 2 for several values of the feedback coefficient $\beta$. It can be seen that for values of $\beta$ greater than $\beta_{\text {LIM }}$ a thin film PC-EL system with optical feedback has a negative slope and a bi-stable nature.

For the PC-EL system, for which the coefficient $\beta>0$, in the moment of a break in the path of optical feedback, a transition from the characteristic for $\beta>0$ to the characteristic for $\beta=0$ (Fig. 2), takes place. 


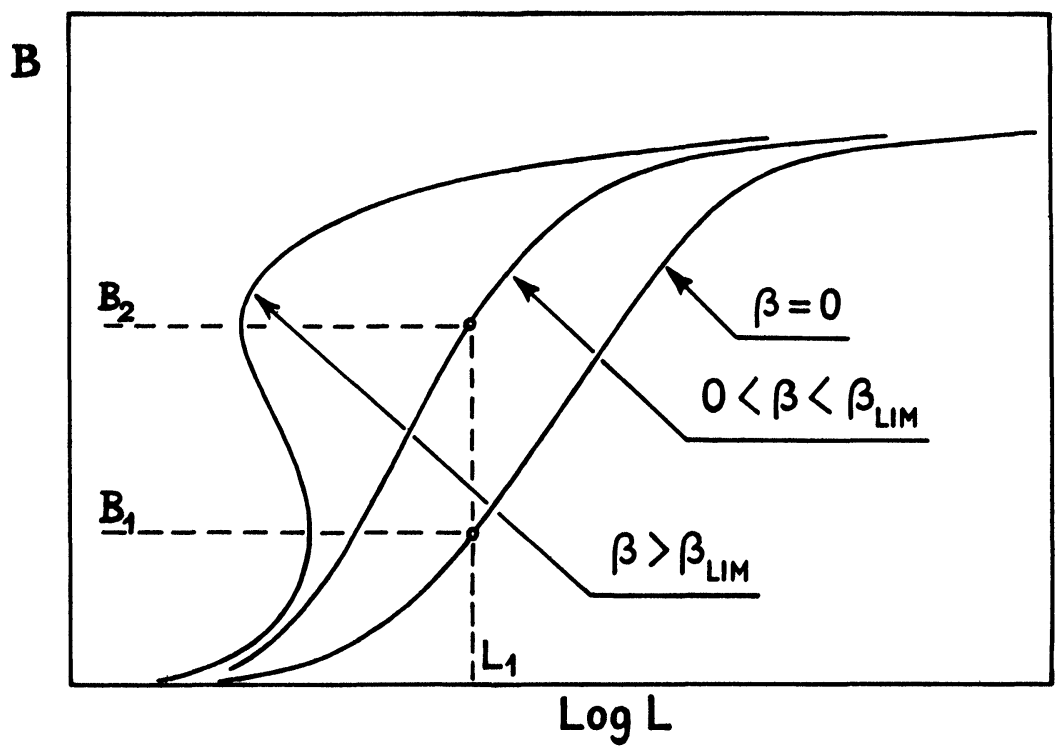

FIGURE 2 B vs. L theoretical characteristics of a PC-EL system.

The dynamic properties of thin film PC-EL system with optical feedback can be described as developed in an earlier work ${ }^{3}$ using three equations:

$$
\frac{\mathrm{d}}{\mathrm{dt}} \Delta \mathrm{n}=\alpha \eta[\mathrm{L}+\beta \mathrm{B}(\mathrm{t})]-\frac{\Delta \mathrm{n}}{\tau_{1}}
$$

where $\Delta \mathrm{n}$ is the density of excess carriers, $\alpha$ is the light absorption coefficient, $\eta$ is the quantum yield and $\tau_{1}$ is the photoconductivity rise time,

$$
\begin{aligned}
C_{E L} \frac{d}{d t} U_{E L}(t)+U_{E L}(t)\left[G_{E L}+G_{0}\right. & \left.+g_{1} \Delta n\right] \\
& =C_{P C} \frac{d}{d t} U_{e}+\left[G_{0}+g_{1} \Delta n\right] U_{e}
\end{aligned}
$$

where $g_{1}$ is a constant parameter and $U_{e}$ is the instantaneous value of the exciting voltage of a PC-EL system, and 


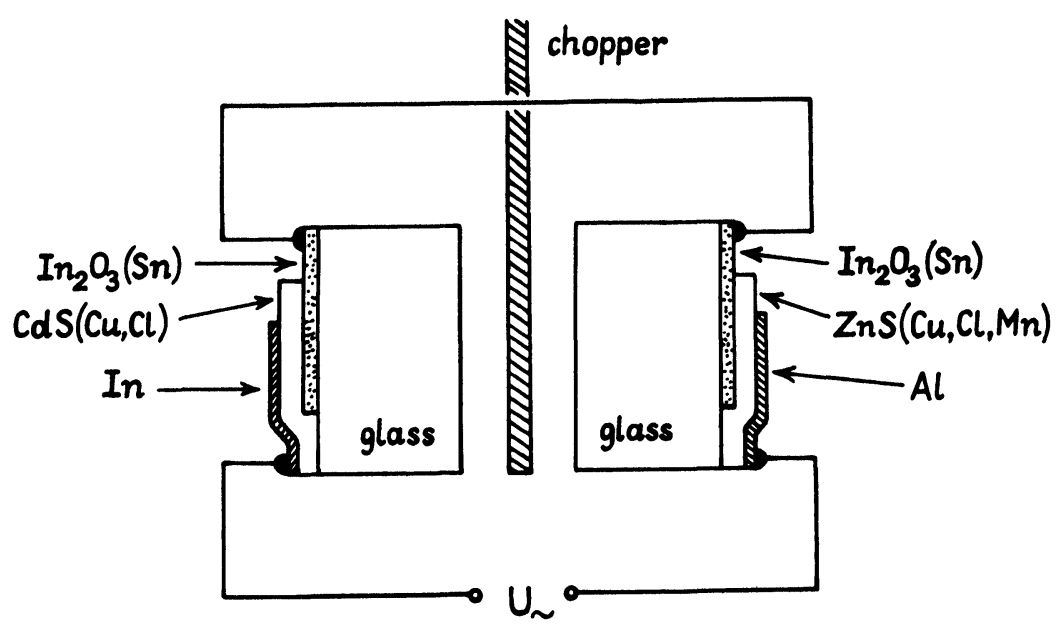

FIGURE 3 The arrangement of the thin film PC-EL system with optical feedback.

$$
B(t)=B_{0} \exp (-\gamma t) \exp \left[-b\left|U_{E L}(t)\right|^{-1 / 2}\right]
$$

The dependence of the luminance $\mathrm{B}(\mathrm{t})$ on the time can be calculated by using equations (6), (7) and (8) for values of coefficient $\beta>0$ and $\beta=0$.

\section{EXPERIMENTAL DETAILS AND RESULTS}

The photoconductive element and electroluminescent cell (Fig. 3) were prepared as a sandwich-type system on a glass substrate. A cadmium sulphide thin film photoconductive element and a zinc sulphide thin film electroluminescent cell were prepared by vacuum evaporation. ${ }^{3}$

A sinusoidal voltage of fixed amplitude and frequency was applied to the PC-EL system. The luminance B of the electroluminescent cell was measured for various intensities $L$ of illumination of the photoconductive layer and for values of $\beta<\beta_{\text {LIM }}$. The results were compared with values computed using the above theoretical model.

Based on the measurements of the dependence of luminance $B$ on the illumination intensity $L$, for $\beta>0$ as well as for $\beta=0$, the dependence 


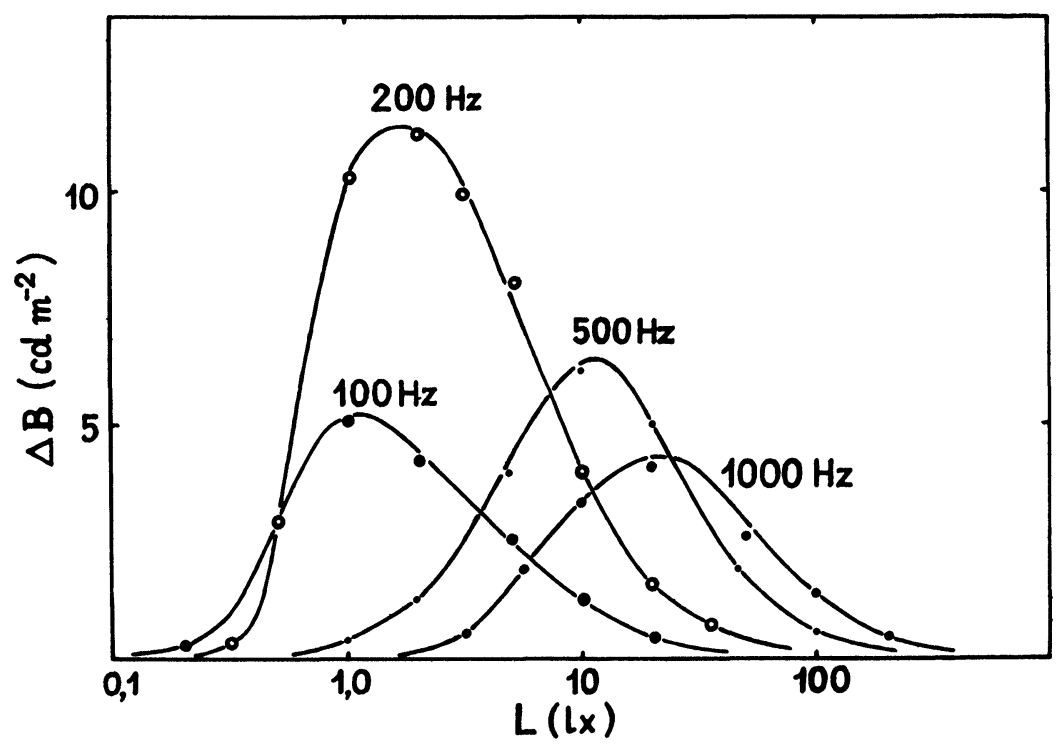

FIGURE 4 Dependence of $\Delta B$ on the illumination intensity for the frequency of 100,200 , 500 and $1000 \mathrm{~Hz} / \beta=0.7 \mathrm{~lx} . \mathrm{m}^{2} . \mathrm{cd}$.

$\Delta \mathrm{B}=\mathrm{B}_{(\beta>0)}-\mathrm{B}_{(\beta=0)}$ on illumination intensity was calculated. The measurements were carried out for the frequencies of 100,200, 500 and $1000 \mathrm{~Hz}$ of the voltage applied to the PC-EL system. The dependences of $\Delta \mathrm{B}$ from $\mathrm{L}$ are shown in Fig. 4.

As can be seen from this figure, the curve $\Delta B(L)$ reveals a maximum. The position of this maximum on the curve shifts with frequency towards higher values of luminance. The highest value $\Delta \mathrm{B}$ was found for the frequency $200 \mathrm{~Hz}$, at $2 \mathrm{~lx}$ of the intensity of luminance.

For fixed values of illumination intensity $L=5 \mathrm{~lx}$ and frequency 500 $\mathrm{Hz}$, the dependence of the luminance B on time for a PC-EL system with optical feedback $\left(\beta=0.7 \mathrm{~lx} \cdot \mathrm{m}^{2} \cdot \mathrm{cd}^{-1}\right)$, and for this system in the moment of a break in the path of optical feedback $(\beta=0)$, was measured. A break in the path of optical feedback was obtained using a rotating disk with cutout sectors (chopper), with the frequency of the breaks considerably lower than the frequency of the voltage supplying the PC-EL system. The obtained characteristic is presented in Fig. 5. 

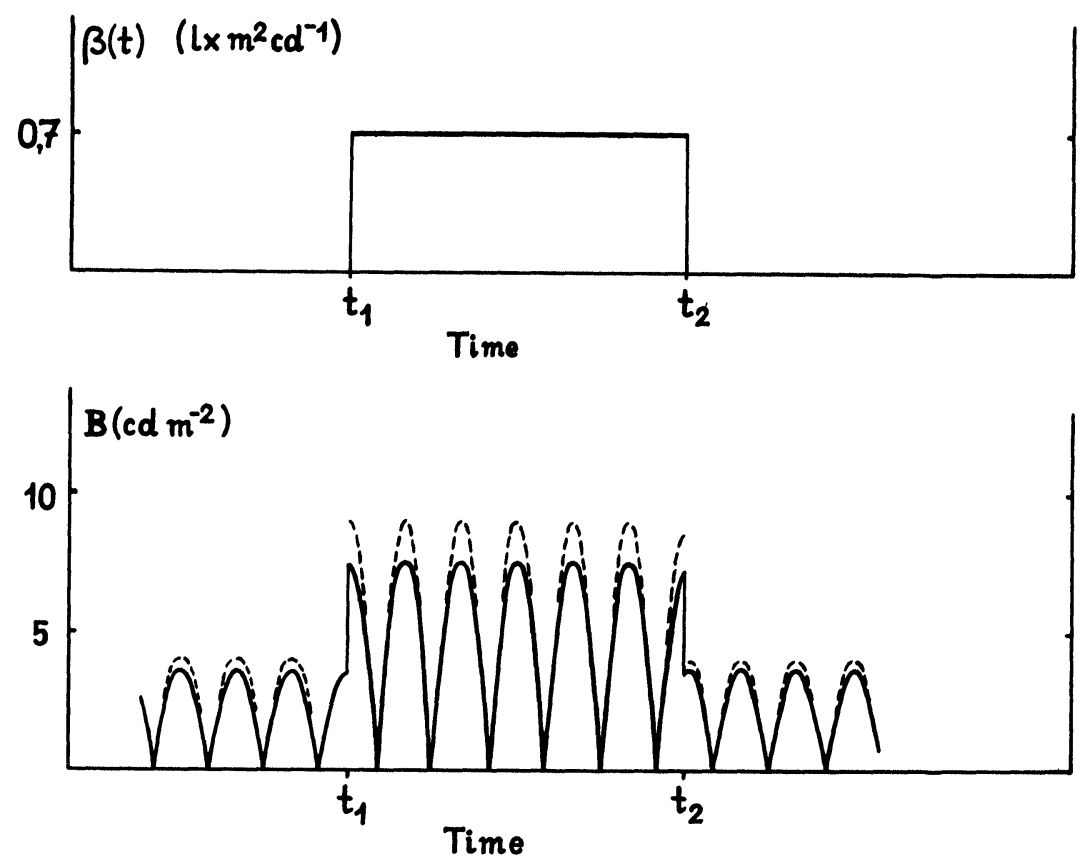

FIGURE 5 Dependence of the luminance B on time for $\mathrm{f}=500 \mathrm{~Hz}$ (- experimental results, - - values calculated using the theoretical model).

\section{CONCLUSIONS}

From experimental measurements and theoretical considerations, a thin film PC-EL system with optical feedback can be a bi-stable system, even for low values of feedback coefficient, upon use of a chopper in the path of optical feedback.

The output signal of the PC-EL system in the form of the luminance B of the light emitted from the electroluminescent cell assumes two different values for the same luminance intensity constituting the input signal. The first is a signal of the PC-EL system with optical feedback $/ \beta>0 /$, and the second a signal of the system without feedback /break in the path of optical feedback, $\beta=0 /$.

The difference of these two values, $\Delta \mathrm{B}$, depends on the frequency of the voltage supplying the system and on the luminance intensity. 
The obtained characteristics show a good agreement with the curves calculated on the base of proposed theoretical model.

\section{REFERENCES}

1. H.K. Henisch, Electroluminescence, Pergamon, Oxford (1962).

2. A van der Ziel, Solid State Physical Electronics, Prentice-Hall, Englewood Clifs, NJ (1976).

3. Z. Porada and E. Schabowska-Osiowska, Active and Passive Elec. Comp., 13(3) (1989).

4. Z. Porada, Thin Solid Films, 71, 209 (1980).

5. G.F. Alfrey and J.B. Taylor, Brit. J. Appl. Phys., 4, 44S (1955). 

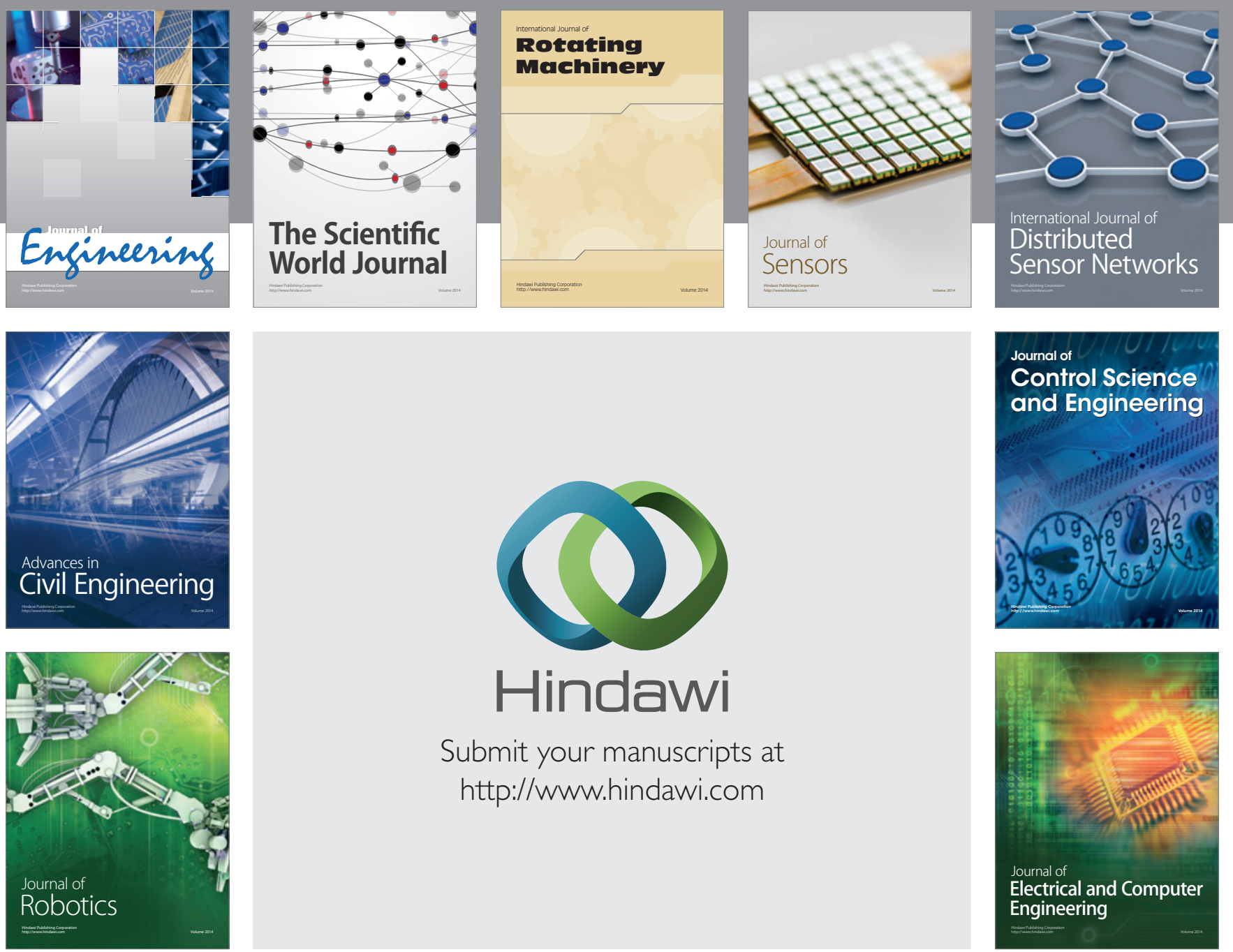

Submit your manuscripts at

http://www.hindawi.com
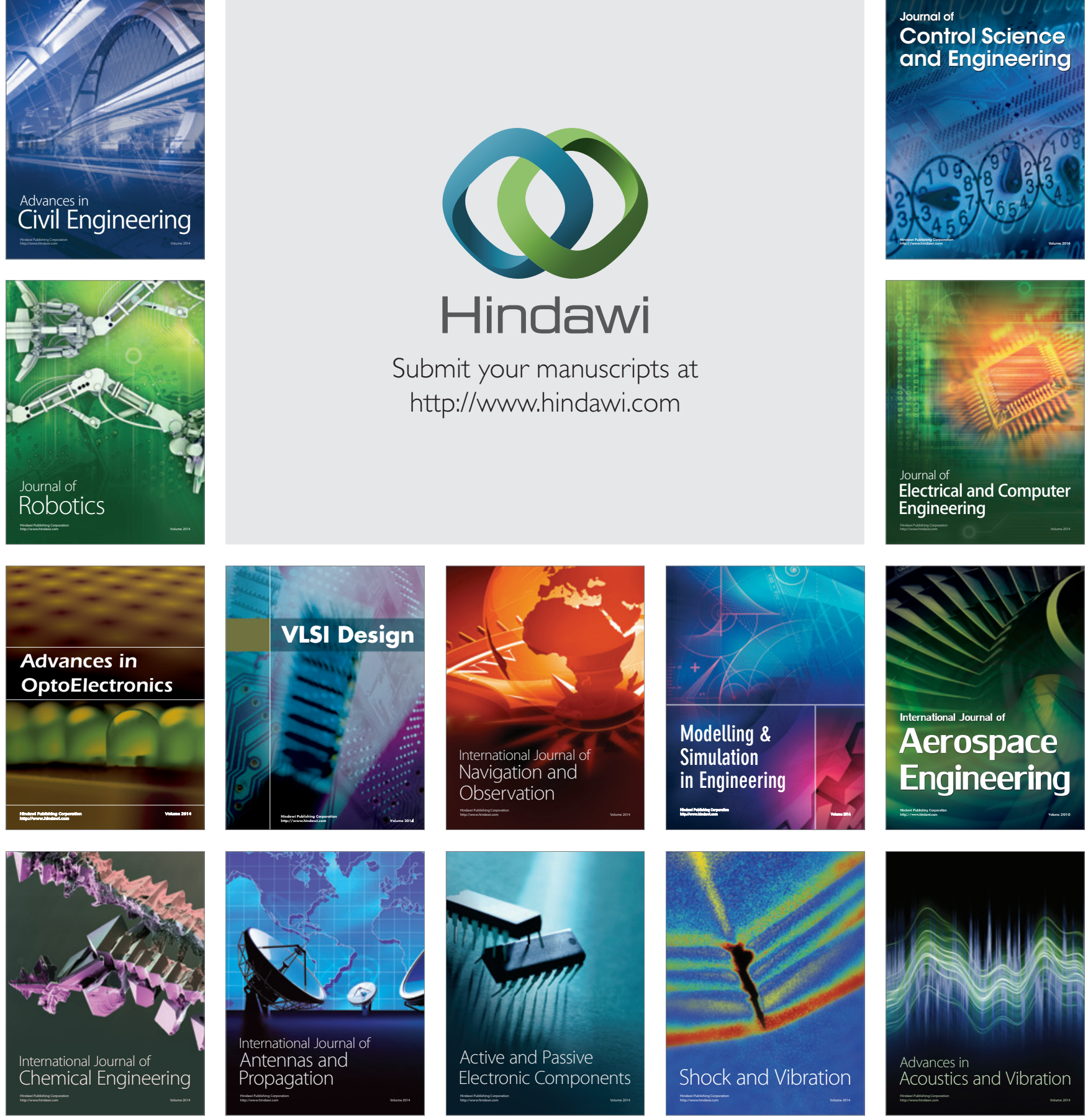